\title{
4,6-Dimethyl-2-Oxo-1,2-Dihydro-pyridine-3-Carboxylic Acid as an Inhibitor Towards the Corrosion of C-Steel in Acetic Acid
}

\author{
S. Abd El Wanees ${ }^{1,2, *}$, Mohamed I. Alahmdi ${ }^{2}$, M. Abd El Azzem ${ }^{3}$ and Hamdy E. Ahmed ${ }^{4}$ \\ ${ }^{1}$ Chemistry Department, Faculty of Science, Zagazig University, Zagazig 44519, Egypt \\ ${ }^{2}$ Chemistry Department, Faculty of Science, University of Tabuk, Tabuk, Kingdom of Saudi Arabia \\ ${ }^{3}$ Department of Chemistry, Faculty of Science, Monufia University, Monufia, Egypt \\ ${ }^{4}$ Lab Section Head, Khalda Petroleum Company, Egypt \\ E-mail: s_wanees@yahoo.com
}

doi: $10.20964 / 110416$

Received: 27 January 2016/Accepted: 28 February 2016 / Published: 1 April 2016

The effect of 4,6-dimethyl-2-oxo-1,2-dihydro-pyridine-3-carboxylic acid (DODHPCA) as a corrosion inhibitor for C-steel in acetic acid is examined by using hydrogen gas evolution, mass loss and potentiodynamic polarization techniques, as well as SEM investigation. Results showed that, the compound under study exhibits inhibitor properties. The inhibition efficiency was found to depend on the inhibitor concentration. The inhibition effect is based on the adsorption of DODHPCA molecules on the metal surface following Langmuir adsorption model. Tafel polarization curves indicated that this compound was of a mixed-type. The thermodynamic parameters are calculated and discussed.

Keywords: Corrosion, C-Steel, Acetic acid, Inhibitor

\section{$\underline{\text { FULL TEXT }}$}

(C) 2016 The Authors. Published by ESG (www.electrochemsci.org). This article is an open access article distributed under the terms and conditions of the Creative Commons Attribution license (http://creativecommons.org/licenses/by/4.0/). 